\title{
Emotion Memory: “A Dangerous Reputation”
}

\section{Eric Hetzler}

Abstract: In October of 2018, Backstage published an article by Alex Yates called "The Definitive Guide to the Stanislavski Acting Technique". This was a very cursory and superficial description of his life and some of his ideas. It was certainly in no way "definitive". In fact, it perpetuated some common misconceptions about his work. For instance, it says he merely "dabbled in the performing arts as an amateur actor, opera singer, producer, and director", with no mention of the Moscow Art Theatre and the years he spent there. However, as the author talks of the merging of the System of Stanislavski with the Method of Strasberg, he notes that emotion memory has a "dangerous reputation" and that "Some high-profile actors have merged their personal lives with that of their characters' lives in psychologically unhealthy ways". In this paper, I aim to trace the lineage of this notion of the danger inherent in studying Stanislavski and attempt to find actual evidence.

Key Words: Stanislavski, Emotion Memory, Affective Memory, Danger of Emotion Memory, Stella Adler

Eric Hetzler is a Senior Lecturer in Drama, Theatre, and Performance at the University of Huddersfield (U.K.). His "Survey of the Actor's Experience" led to several publications examining how actors describe emotion in performance and the importance of awareness on stage. In his continuing exploration of emotion and acting he has been studying the Alba Method of Emotion and is a certified level 3 Teacher. 


\section{Introduction}

In October of 2018, Backstage published an article by Alex Yates called "The Definitive Guide to the Stanislavski Acting Technique". This was a very cursory and superficial description of his life and some of his ideas. It was certainly in no way "definitive". In fact, it perpetuated some common misconceptions about his work. For instance, the author notes that Stanislavski merely "dabbled in the performing arts as an amateur actor, opera singer, producer, and director", with no mention of the Moscow Art Theatre and the years he spent there. However, as the writer talks of the merging of the System of Stanislavski with the Method of Strasberg, he makes a comment I hadn't heard since I was an undergraduate - that emotion memory has a "dangerous reputation" and that "Some high-profile actors have merged their personal lives with that of their characters' lives in psychologically unhealthy ways". ${ }^{1}$ It reminded me of my own early training where we were told specifically not to read An Actor Prepares because this kind of work had very bad psychological effects and had even driven actors to suicide. There was no evidence for this assertion and in all of the years I have been studying his work, I have not encountered any. But the sternness of the warnings meant I didn't study his work until more than a decade later. In my doctoral research, I surveyed more than 350 actors, many who had trained in System/Method-based programs, and none of them mentioned any emotional distress.

At the same time, it should be noted that in spite of the belief noted in Backstage, many acting teachers still make emotion memory exercises part of their training methods. Hollywood acting coach Ivana Chubbuck, in her book The Power of the Actor, uses terms like Substitution and Inner Objects when discussing character development, but close examination of her method shows that she is asking actors to draw on their emotional memories and past traumas and use 
them in their work. She notes that substitutions need to be made from "an emotional point of view" 2 and that the function of Inner Objects is emotional. Numerous training programs use $A n$ Actor Prepares as their primary text where the use of emotion memory often stands front and centre. And, of course, the descendants of Lee Strasberg continue to teach his method, which includes the use of affective memory exercises. Thus, there is a strange relationship in the acting world where, in the public mind, actors are endangering themselves by using a potentially dangerous technique, while the people training these actors seem to be ignoring this perceived danger. Perhaps, in order to better understand this complex relationship, the origin of this idea of danger could be found which might go some way to explaining why it persists. In this paper, I aim to trace the lineage of this notion of the danger inherent in studying Stanislavski's work on emotion memory and attempt to discover where it came from.

\section{The Perceived Danger}

To begin, emotion memory or affective memory is usually described as the actor using their own memories of emotional incidents that are analogous to a character they are playing and using those memories to induce the needed emotional state. The term is mostly associated with Stanislavski and his text An Actor Prepares. However, later acting teacher Lee Strasberg used the idea in much the same way, calling it affective memory, which means the two teaching approaches often get conflated and used to mean the same thing.

When attempting to trace the idea of the danger of actors using emotion memory, simple on-line searches find a plethora of material. Many begin with a picture of Heath Ledger as the Joker in the film The Dark Knight, as is the case in this 2016 blog post on The Odyssey Online with the title "The Emotional Dangers of Method Acting". The author of this page, Sarah Adriance, notes: 
You have to be careful when using your own emotional memories to access levels for these scenes. There is such thing as going too far...There is a reason that many people believe that Heath Ledger's method acting for the Joker greatly contributed to his death. Is it worth your mental health to stir up terrible memories so that you can play the character with greater verisimilitude?

Others, like acting teacher Brian Timoney, in his 2018 blog post entitled "The Dangers of Affective Memory", states:

You might use affective memory while playing the role of Ophelia in Hamlet, for example.

She has a suicidal fate, and connecting to that level of depression means delving into memories that could trigger a very real depression in you.

He further states that dangerous effects of affective memory can include:

- Hyperventilation

- Anxiety attacks

- Panic attacks

- Depression

- Substance abuse

And then there is this from a 2014 on-line article from Newsweek entitled "Method Acting: 'Faking It' Is So Last Year - Commitment Is Everything” notes that:

There are inherent dangers in this approach if taken too far, resulting in potential distortion of the persona and - in extreme cases - schizophrenia and total detachment from reality. ${ }^{3}$

With the exception of Heath Ledger, none of these blog posts or articles offer any evidence for any of their claims about the danger of using emotion memory in acting. And, of course, the problem with using Heath Ledger is that he didn't die because he had somehow 
merged himself with the character of the Joker. He died of a drug overdose while working on his next project, Terry Gilliam's film The Imaginarium of Dr. Parnassus, where he was playing a very cheerful character that was in no way similar to the Joker.

What we see, in looking at the general idea, is that a lot of people outside of the world of acting and actor training, believe emotion memory is dangerous. Here begins a journey of digging into the past, attempting to find early mentions of this supposedly dangerous technique and who said what and how it got out into the mainstream.

The biggest problem encountered in this research is that the notion of emotion memory being dangerous seems to be based more in the popular consciousness than in the academic world. All of the above quotes come from popular media sources, which means this idea is out in the wild rather than confined to the journals of the academy. This makes tracking it a bit harder because where do you look? How do you find the origin? Ideally it would come from a specific academic source that was picked up and spread by journalists into the mainstream. But that does not seem to be what happened. When I began the research, I thought it would be quite easy to find, but that has not been the case.

\section{Who Said What}

The simplest explanation would be that it comes from Stanislavski himself. As is well known, he shifted his attentions away from emotion memory in his early work and towards the new method of physical actions. As noted by Benedetti, "Emotion Memory had too often produced hysterics or self-indulgence". ${ }^{4}$ Is it possible the idea stems from this concern? Probably not as Stanislavski never published these thoughts himself - they appeared in letters and personal 
journals. They don't really appear publicly until writers like Benedetti start mentioning his personal thinking about it well into the latter stages of the $20^{\text {th }}$ century.

Perhaps it comes from Moscow Art Theatre actor and teacher Michael Chekhov's assessment of the work? It is certainly quoted in many sources that he had such a significant mental breakdown in 1918 that he was "unable to act and on one occasion, left the stage in the middle of a performance". ${ }^{5}$ Some have intimated that this was caused by his work with emotion memory. Carnicke, in Stanislavski in Focus, leaves the door open for readers to think this about Chekhov, relating that "cautious experiments with personal feelings triggered a nervous breakdown in his talented protégé". ${ }^{6}$ The problem is that his breakdown seems more to have resulted from a close succession of misfortunes that included the deaths of his parents, his wife leaving him, and a close friend killing himself with Chekhov's own gun. ${ }^{7}$ Chekhov, himself, in any of his published work about acting, doesn't appear to have ever said anything about emotion memory being dangerous. However, there is a comment he made in a letter to a friend about a meeting he had with Stanislavski in 1928. As reported by Andrei Kirillov in a 2005 talk at Dartington, Chekhov says in this letter that: "My opinion is further confirmed by the fact that 'affective memories' often lead to nervous and even hysterical reactions among the actors (and particularly actresses)". Here we see one of the first references to problems with emotion or affective memory. He isn't calling it dangerous, but he is noting that the use of personal memories can be problematic. But, this view of his was not published. And we should probably recognise that Michael Chekhov is not well-known outside of acting circles. This would make it unlikely that his concerns would have gotten out into the mainstream press. Therefore, it appears we cannot lay the foundations of this at his feet, though it might have contributed to some of the potential thinking about emotion memory. 
This leads forward in time to the Group Theatre and the adoption of the work of Stanislavski (through the lens of Boleslavsky and Ouspenskaya) as their touchstone for actor training and rehearsal. As is fairly well known, the Group lasted from 1931 to 1941 and many of the members went on to become successful actors, directors, and teachers, who had a significant impact on the world of acting. Many like Franchot Tone, Lee J. Cobb, John Garfield, and Elia Kazan went to Hollywood and developed careers in film. Others stayed in New York, working on Broadway. This is where evidence about the dangers of emotion memory begins to emerge. Initially, what we see are complaints about actors that have trained in what director and head of teaching at the Group, Lee Strasberg, called The Method. Robert Brustein, in a 1958 Commentary article entitled “America's New Culture Hero: Feelings Without Words”, while writing about the shift in American theatre towards inarticulate, proletarian characters, notes some of the problems the approach causes in performances:

One becomes more conscious of the personal problems of the actor than of the character he is playing; in some cases, the actor's and the character's problems become inextricably confused... The actor becomes a creator rather than an interpreter, seeking the clue to his performance in his own experience instead of in the experience of the character he is supposed to be playing. ${ }^{8}$

There are enough public complaints by theatre critics and others that later in 1958 Robert Lewis, former Group Theatre member, gives a series of lectures and publishes a book of the same name, entitled: Method or Madness. Here, he aimed to explain how the Method was created and meant to be used. But he also recognised the criticism of Method actors made by critics like Brustein, noting: 
...the unrelated slouch, the self-conscious hands in the pockets, the sawing of the air, the running of the fingers through the hair...you can always see them concentrating very hard regardless of the amount of concentration needed. ${ }^{9}$

In this work, Lewis doesn't address emotion memory at all, but we see that after the demise of the Group Theatre and rise of former members as star actors and teachers, he felt there was a need to respond to complaints and criticism of how Method actors were working.

In fact, a very commonly quoted later complaint came from Theodore Hoffman in his 1960, Columbia University Forum, article “At the Grave of Stanislavsky or How to Dig the Method". In it, he described the bad method actor thusly:

Method actors seem more intense than others. They like to get close to each other (closer than the traditional arms-length). They are apt to speak low when there is distance between them and loud when they are close to each other. There is a tautness in their voices which makes them inaudible or gratingly monotonous. They like to scratch themselves, rub their arms, brush their hair, count their buttons..$^{10}$

And the description goes on. But there is nothing in the criticism about any dangers. It is more about the turning inward of the performances to the point that actors turn their backs on the audience and cannot be heard.

Then in 1961, British actor Charles Marowitz writes The Method as Means: An Acting Survey. In his attempt to explain Method acting, he notes that the use of emotion memory in performance presents a kind of "danger".

It distracts the actor from his natural course and, in seeking an artificial boost in order to attain a difficult height, the actor is frequently catapulted past his mark. Even if he lands squarely, it is often in a frame of mind which makes the next ascent confusing or impossible. ${ }^{11}$ 
He further asserted:

The Method became an eccentricity to be paraded or an occult secret whose public mockery conveyed a sweet sense of martyrdom. The clannishness of the Actors' Studio and its subsequent immersion in publicity made the whole business more suspect still. ${ }^{12}$

At this point in history, the complaints, it seems are mostly about "method" actors who were poorly trained or actors attempting to be "method" actors without any training in it all. There is nothing about the use of personal emotions or even anything about the training itself. Rather, the criticism is about bad acting.

In 1962, Lewis publishes a new article in TDR called "Emotional Memory" where he explained why he chose not to attempt to explain emotion memory in his Method or Madness lectures and book. "Rather than take the risk, in a public talk, of adding to the dangerous nonsense that has been spread around over the years on this subject, I contented myself with a definition and let it go at that". ${ }^{13} \mathrm{He}$ then went on to describe how it ought to be used. But it is mostly a how-to as defence, perhaps in response to the further criticisms of people like Hoffman. Thus, at this point, any notion that the use of emotion memory presents a danger to the actor does not seem to have been in discussion amongst critics. The problems of poorly trained Method actors are being examined, but that seems to be the extent of it.

If we turn to the former members of the Group Theatre talking about their experiences, however, then we start to see a different picture. In 1934, after spending 5 weeks in Paris working with Stanislavski, Group member Stella Adler returned to the US to tell the other members about his work and what he said to her. She reported that he had abandoned affective memory in favour of the Method of Physical Action. And, as reported by many members of the 
Group, she openly challenged Lee Strasberg on his use of emotions. This caused a rather large rift in the company as some shifted allegiances to her and others remained faithful to him. None of this was likely known outside of the immediate circle that was the Group. However, once the company fell apart and they all went in separate directions, this rift became more visible.

Strasberg became the head of teaching at the Actor's Studio in 1947. Sanford Meisner taught at the Neighbourhood Playhouse - he had been teaching there since 1935, but became head of acting in 1940 - and Stella Adler began her own teaching at the Stella Adler Studio of Acting in 1949. These three became the primary teachers of what is now considered to be the Method. And though they trace their ideas back to Stanislavski, they are all quite different. Of course, those differences will not be discussed here. What is interesting at this stage is to look at how the fallout from Adler's trip to Paris seems to be where the notion of the dangers of emotion memory comes from.

In 1960, in the a popular-media magazine The Theatre: A Magazine of Drama, Comedy, and Music, Adler published an article called "The Art of Acting (The Actor's Needs)". In it, she described what young actors need to do to succeed and she made an interesting comment: "Most students, in fact most people, hear a good deal about "The Method". The Method is complex". She goes on to explain that it is a technique that actors can use and that it is based on older techniques. She also says "If applied badly, it can be very disturbing and not without danger...There is something vulgar, corrupt, and yes, even sick in this". ${ }^{14}$ Here we see a very early comment about how she feels about the Method. There is no mention of emotion memory, but clearly, she has strong feelings about the training. It is also worth noting that she is saying this in a popular press magazine. The Theatre was not an academic journal. It was billed as a 
magazine for people interested in plays and actors on Broadway, as well as those people thinking to pursue a career as an actor.

In 1964, TDR publishes an article called "The Reality of Doing”, a series of interviews with Vera Soloviova - an actress who studied at the Moscow Art Theatre as an original member of the First Studio, Sanford Meisner, and Stella Adler. In the interviews, Adler and Meisner make some pointed statements about the use of emotion memory. Adler says: "To go back to a feeling or emotion of one's own experience I believe to be unhealthy. It tends to separate you from the play, from the action of the play, from the circumstances of the play, and from the author's intention". ${ }^{15}$ Meisner echoes this when he says: "The problem of the deliberate stimulation of emotion is to me the most delicate and dangerous element in the actor's craft". 16 Neither calls emotion memory itself dangerous, as such, but the criticism is becoming more pointed.

Three years later, January 8, of 1967, in the daily newspaper, New York World Journal Tribune, a profile of Adler appears. Entitled "Stella at Yale", the author, John Gruen, lauds Adler for both her teaching and her life. There is nothing in it specifically about emotion memory or Strasberg or even about the Group, beyond a mention of it as part of her life story. However, it does talk about her meeting with Stanislavski in Paris, noting "It is Stella Adler who holds the distinction of being the only American actress to have ever worked directly with Stanislavsky" ${ }^{17}$ She describes their meeting and goes on to make what appears to be a veiled comment about the work going on with the Group and the acting they were being trained to do under the guise of it being Stanislavski’s. It was, she said:

...taken to be a grim, breast beating, morbid form of expression. There was no joy to be found anywhere. I could not believe that Stanislavsky really meant the actors to wail so, and sigh, and cry, and carry on. ${ }^{18}$ 
She then goes on to describe his reaction to her complaint ("he stood up and asked if I would like to take a little walk with him") and how he spent time training her in the importance of the given circumstances of the play. Later in the article, the author makes an interesting claim stating "if she's called the greatest teacher of acting in America, there's good reason for that". ${ }^{19}$ He mentions Stanislavski of course, as well as Boleslavsky and Ouspenskaya, but there is no mention of Lee Strasberg. Here, in a piece of popular media, Adler makes very specific comments about the style of acting she had been experiencing and how it was Stanislavski who showed her the way. It is not a direct attack on the Method, but it certainly seems to be alluding to it.

Later, in 1976, Helen Crich Chinoy edited an expansive issue of Educational Theater Journal that celebrated the Group Theatre. In "Looking Back 1974-1976", there are interviews of many of the primary members of the company. It includes transcripts of presentations done at a reunion in Minneapolis in 1974 that featured Harold Clurman, Morris Carnovsky, and Robert Lewis, and follows with additional material from other members. Here, many talked about the problems of the work they did using emotion memory and in particular, how Strasberg's approach led to deep psychological issues amongst some of them.

Meisner made the first case about the problems of the Method.

The Group took introverted people and intensified their introversion. I don't know whether the others would agree with me, I haven't spoken with them, but the result was that many, many young actors in the Group were damaged by the approach. ${ }^{20}$

This statement was referenced by Lewis in the opening words of his presentation. Meisner was not at the reunion, but a recording of his words was played. Lewis refers to it here: 
I'm shook up by what Sandy Meisner said in the recording played during the introduction. He said that some of the work in the Group Theatre ruined the young people in the theatre, and since I was the youngest one there, I can only think that you are looking at the most ruined of them all. ${ }^{21}$

He follows with a story about talking to Katherine Hepburn when she said:

\begin{abstract}
"You know you and Gadget Kazan were the only two who were mean enough to come through those whole ten years in the Group Theatre completely untouched." I said, "You're absolutely right, Katharine. Outside of three complete nervous breakdowns, it didn't touch me at all."22
\end{abstract}

While he might not be talking specifically about emotion memory, he is certainly talking about the work that was done there and how it affected him, particularly since Meisner was very much talking about the kind of work they were being led in.

Then the article comes to Stella Adler. Though shown here in an academic journal, it is re-printed from an interview taken from the Sunday New York Times in 1976. Here, she becomes far more pointed in her criticisms:

I agree with Sandy Meisner's observation that the work was unhealthy. There was a certain stress on the use of the actor's personal emotion which landed them in the booby-hatch and shattered them. It affected a lot of us. It affected me too. I was deeply disturbed and unhappy by the way the Stanislavsky's ideas and methodology were used. The emphasis was a sick one. $^{23}$

She re-iterates what she wrote about in 1960, calling it "sick".

In her interview, Phoebe Brand says of emotion memory:

I would say that I believe in the Method absolutely. But when I say Method, I don't mean the "emotional memory" aspect of it... You could really do yourself harm in that way, and I think the work disturbed several people...I didn't need this. ${ }^{24}$ 
And then Margaret Barker said "I think some actors were hurt. Strasberg was so intent on getting what he called "real emotion", that he reduced us to a pulp",25

It seems that at this time, former members of the Group Theatre were letting their feelings be known about the work they had done 45 years earlier. Still, except for the Adler interview, these were all done as part of an academic journal article that few people outside the academy would likely ever see. But it is the Adler interview that is important here, because she becomes the most vocal opponent of emotion memory, publicly, of anyone.

In 1979, an article appears in the New York Times. Entitled "Can the Method Survive the Madness?", Adler and Strasberg are essentially set off against one another. In addition to noting that Strasberg will not mention Adler by name, calling her "her" or "that woman", the article talks about the issues of Method Acting. Here, Adler pulls no punches in her opinions:
"Lee Strasberg?" Stella Adler says. "I think what he does is sick. Too many of his students have come to me ready for an institution." Adler claims that Strasberg has so exceeded Stanislavsky's original intent that his teaching is psychologically and emotionally dangerous. Stella Adler says. "He produces this neurotic actor. He's not a therapist. His teaching is painful and dangerous." 26

For the most part, her ire is directed at Strasberg and not emotion memory as such. However, the two are heavily intertwined. In fact, in a July 17, 1989 profile of her in People Magazine, she reiterates her feelings about the work. Here she does combine the work of Strasberg with emotion memory:

Essentially, Strasberg made Stanislavsky's studies in "affective memory," in which an actor must plumb his psyche for emotions and situations in his past that are analogous to the character's, the core of the "Method" he would later teach at his Actors Studio. Adler was disgusted by this mix of art and psychoanalysis. "Sick," she called it. ${ }^{27}$ 


\section{Conclusion}

It appears that much of the view that emotion memory is dangerous comes from Stella Adler. There seems to have been a concerted effort that lasted for more than 25 years where she publicly talked about the approach being first "unhealthy", then "sick" and even "sick and dangerous". Significantly, she was doing it in the popular press, not in academic journals. This means far more people saw this than would have otherwise. Working actors tend not to read academic journals, nor do the general public, meaning that attempts to defend it, as Robert Lewis did in academic articles, are not getting through.

It does not necessarily need to be defended, though. Actors are still being trained to use emotion memory as a way of connecting to the emotions of a character. My own students, coming from their A-Level training report having used moments from their pasts to help them find the emotion for a scene. Their teachers have them read An Actor Prepares and then use the exercises in their work. Oddly, they are also keen to talk about how dangerous it might be for actors to use. And, as noted in the introduction, the descendants of Strasberg at the Lee Strasberg Theatre and Film Institutes in New York and Los Angeles, are still training actors in this work without any apparent concern about any potential danger it might pose.

This creates a strange tension between the practice and the perception. For actors, it still seems to be a valuable tool in training. In the public mind, the use of emotion memory by "Method" actors could lead to terrible psychological trauma in the pursuit of a performance. And in all of this, it seems very possible that much of the popular notion that emotion memory is unhealthy and dangerous starts with Stella Adler. Her continued attacks and profiles in the popular press might be the reason why so many in and outside of the entertainment industry to believe that this kind of work is indeed, dangerous. 


\section{Notes}

${ }^{1}$ Yates, Backstage, 2018

${ }^{2}$ Chubbuck, Power of the Actor, 56

${ }^{3}$ Norman, Newsweek, 2014

${ }^{4}$ Benedetti, Stanislavski, 325

${ }^{5}$ Chamberlain, Michael Chekhov, 13

${ }^{6}$ Carnicke, Stanislavsky, p.153

${ }^{7}$ Chamberlain, Michael Chekhov, 13

${ }^{8}$ Brustein, Commentary, 123

${ }^{9}$ Lewis, "Emotion Memory", 64

${ }^{10}$ Hoffman, Columbia University Forum, 32

${ }^{11}$ Marowitz, The Method as Means: An Acting Survey, 122

${ }^{12}$ Ibid, $39-40$

${ }^{13}$ Lewis, Tulane Drama Review, 54

${ }^{14}$ Adler, The Theatre: A Magazine of Drama, Comedy, and Music, 17

${ }^{15}$ Gray, TDR, 143

${ }^{16}$ Ibid, 144

${ }^{17}$ Gruen, New York World Journal Tribune, 14

${ }^{18}$ Ibid, 14

${ }^{19}$ Ibid, 15

${ }^{20}$ Carnicke, Educational Theatre Journal, 504

${ }^{21}$ Ibid, 484

${ }^{22}$ Ibid, 484 
${ }^{23}$ Ibid, 508

${ }^{24}$ Ibid, 515-516

${ }^{25}$ Ibid, 523

${ }^{26}$ O’Malley, New York Times, 8

${ }^{27}$ Brock, People Magazine, 1989

\section{Bibliography}

Benedetti, J. Stanislavski: His Life and Art. London: Methuen,1999.

Brock Pope. "Stella Adler” People Magazine, July 17, 1989, https://people.com/archive/stella-adler-vol-32-no-3/, accessed 03/06/19

Brustein, Robert, “America’s New Culture Hero: Feelings Without Words”, Commentary, Feb. 1958.

Carnicke, Sharon. Stanislavsky in Focus. London: Routledge, 2009.

Chamberlain, F. Michael Chekhov. London: Routledge, 2004.

Chubbuck, Ivana. The Power of the Actor, New York: Gotham Books, 2004.

Crich-Chinoy, Helen. "Reunion: A Self-Portrait of the Group Theatre" Educational Theatre Journal, Vol. 28, No. 4, (Dec., 1976), pp. 471-552

Gruen, John. 1967 "Stella at Yale” New York World Journal Tribune. pp.12-17 Jan, 8.

Hirsch, F. A Method to Their Madness. Boston: Da Capo Press, 1984.

Hoffman, Theodore. "At the Grave of Stanislavsky or How to Dig the Method", Columbia University Forum, (Winter 1960) pp.31-37

Kirillov, Andrei “Michael Chekhov: From Stanislavsky's System to his own Technique of Acting”, Dartington Hall Conference, 2005, http://www.michaelchekhovstudio.org.uk/the-michael-chekhov-approac/articles-extracts/andrei-kirillovs-article.html, accessed 06/03/19

Lewis, Robert, "Emotional Memory", Tulane Drama Review, vol. 6, no. 4, (1962), pp. 54-60.

Neil Norman, "Method Acting: 'Faking It' Is So Last Year - Commitment Is Everything”, Newsweek, ON 10/5/14 AT 6:58 AM, https://www.newsweek.com/2014/10/10/method- 
acting-why-faking-it-so-last-year-commitment-everything-274976.html, accessed $\underline{02 / 03 / 19}$

Suzanne O’Malley. 1979 “Can the Method Survive the Madness?” New York Times. p. 8 Oct 7.

Soloviova, V., Adler, S., Meisner, S., \& Gray, P. “The Reality of Doing”. The Tulane Drama Review, 9(1), (1964). 136-155.

Yates, Alex. 2018. The Definitive Guide to the Stanislavski Acting Technique”, Backstage. October 2018, https://www.backstage.com/magazine/article/the-definitive-guide-to-the-stanislavsky-actingtechnique-65716/, accessed 29/10/18 